\title{
"MINHA VIDA É ANDAR POR ESSE PAÍS...": A EMIGRAÇÃO RECENTE NO SEMIÁRIDO SETENTRIONAL, POLÍTICAS SOCIAIS E MEIO AMBIENTE
}

\author{
Ricardo Ojima* \\ José Vilton Costa** \\ Renata Kissya Calixta ${ }^{* * *}$
}

\begin{abstract}
A categoria refugiados ambientais vem sendo utilizada para descrever os deslocamentos populacionais causados por condições climáticas extremas. As estimativas apontam que haverá um aumento significativo dessa modalidade de movimentos nos próximos anos, sobretudo pelo agravamento das condições ambientais decorrentes das mudanças climáticas. Entretanto, há grande controvérsia no que diz respeito ao peso que os fatores ambientais podem ter na decisão migratória. Nesse sentido, o artigo busca trazer uma reflexão sobre a pertinência da categoria refugiado ambiental no contexto da emigração do semiárido setentrional, a região mais castigada pelas secas. Para isso utilizamos os dados oficiais de decreto de Situação de Emergência (SE) e Estado de Calamidade Pública (ECP) e dados do Censo Demográfico 2010 para analisar o perfil e o papel que fatores ambientais e sociais podem ter sobre os emigrantes. Os resultados indicam que a ausência de programas de transferência de renda possui um papel mais importante do que a ocorrência oficial de secas entre os emigrantes dessa região. Assim, embora os resultados mereçam maiores investigações, as evidencias apontam que estratégias que contribuam para uma maior resiliência das pessoas são efetivas para o enfrentamento das secas.
\end{abstract}

Palavras-chave: emigração, semiárido setentrional, deslocamentos ambientais, políticas sociais.

\footnotetext{
* Professor Adjunto da Universidade Federal do Rio Grande do Norte (UFRN). Natal/Brasil.

** Professor substituto do Departamento de Saúde Coletiva e Nutrição (UFRN). Natal/Brasil.

*** Mestranda em Demografia da Universidade Federal do Rio Grande do Norte (UFRN). Natal/Brasil.
} 


\section{Introdução ${ }^{1}$}

O conceito de refugiado ambiental ganha destaque na literatura internacional, principalmente após a repercussão da publicação do Relatório do IPCC de 2007 (AR-4). Entretanto, o termo já havia sido utilizado desde a década de 1980, a partir do trabalho de El-Hinnawi². De fato, há ainda grande discordância em relação ao uso do termo refugiado para as migrações motivadas por causas ambientais, sobretudo pelo seu uso indiscriminado que diverge da definição legal proposta pela Convenção de Genebra que orienta o conceito de refugiado das Nações Unidas ${ }^{3}$. Ou seja, o refugiado seria aquele indivíduo que,

perseguido em virtude da sua raça, religião, nacionalidade, filiação em certo grupo social ou das suas opiniões políticas, se encontre fora do país de que tem a nacionalidade e não possa ou, em virtude daquele receio, não queira pedir a proteção daquele país; ou que, se não tiver nacionalidade e estiver fora do país no qual tinha a sua residência habitual após aqueles acontecimentos, não possa ou, em virtude do dito receio, a ele não queira voltar (Convenção de Genebra, 1951, cap. 1, art.1, A2).

Em verdade, um dos aspectos mais complexos na análise dos fluxos migratórios é justamente o entendimento das suas motivações. Sobre este ponto, $\mathrm{Lee}^{4}$ coloca a necessidade de se entender os fatores contextuais que constrangem os movimentos populacionais, ou seja, fatores de atração, repulsão e os obstáculos que se colocam entre os locais de origem e destino. Dentro deste contexto, os fatores ambientais seriam apenas mais um dos elementos que influenciariam a migração e que, considerando os cenários de agravamento de situações ambientais extremas derivadas de mudanças climáticas globais, deveriam ser investigadas com maior atenção ${ }^{5}$.

Como destacado por Oliveira e Jannuzzi ${ }^{6}$, são raros os estudos que abordam o tema dos motivos migratórios de uma perspectiva quantitativa. O que, de certa maneira, resulta da avaliação de que o perfil seletivo dos movimentos migratórios está relacionado ao emprego e ao grupo populacional jovem em

1 Este trabalho foi desenvolvido no âmbito dos projetos: "Impacto dos Programas de Transferência de Renda sobre a Dinâmica Populacional e Redução da Pobreza no Semiárido Setentrional Nordestino" (CNPq, processo: 457110/2013-9) e "Urbanização, condições de vida e mobilidade espacial da população no contexto dos biomas nordestinos: repensando as heterogeneidades intra-regionais" (CNPq, processo: 403853/2012-5).

2 EL-HINNAWI, Essam. Environmental refugees.

3 MORRISEY, James. Rethinking the 'debate on environmental refugees': from 'maximilists and minimalists' to 'proponents and critics'; SUHRKE, Astri. Environmental degradation and population flows.

4 LEE, Everett S. Uma teoria sobre a migração.

5 HOGAN, Daniel J. Mobilidade populacional, sustentabilidade ambiental e vulnerabilidade social.

${ }_{6}$ OLIVEIRA, Kleber F.; JANNUZZI, Paulo. Motivos para migração no Brasil e retorno ao Nordeste: padrões etários, por sexo e origem/destino. 
idade ativa. Entretanto, quando se trata de explicar os fatores de repulsão dos grandes fluxos migratórios inter-regionais no Brasil ao longo do século 20, recorrentemente encontramos justificativas nas secas que assolam a região semiárida nordestina. Para Martine ${ }^{7}$, complica-se nessa análise das motivações, o fato de que só seria possível captar essas percepções a partir daqueles migrantes sobreviventes ao processo no momento em que é feita a pesquisa, ou seja, não haveria como reconhecer as motivações e até mesmo a existência do migrante que não se encontra mais no local de destino do fluxo que se pretende estudar.

Bates $^{8}$ e Adamo $^{9}$ demonstram preocupação sobre a utilização da categoria "refugiado" com motivações ambientais, sobretudo por reconhecer a multiplicidade de fatores envolvidos no movimento populacional. Salehyan ${ }^{10}$ e Myers ${ }^{11}$ consideram como refugiados ambientais os deslocados por novas configurações ambientais derivadas basicamente de mudanças climáticas ${ }^{12}$. Enfim, a principal crítica ao uso do termo "refugiado ambiental" seria descaracterizar o conceito normativo de "refugiado" a partir de um oportunismo temático, pois a relação entre migração e fatores climáticos nunca foi desconsiderada.

Mas por outro lado, embora os fatores ambientais sempre sejam mencionados como elementos importantes na decisão de migrar, poucas vezes são testados em análises quantitativas. E talvez esse seja o posicionamento político que os defensores do termo "refugiados ambientais" buscam destacar: a necessidade de dar maior atenção aos fatores ambientais nos estudos de migração é essencial para o contexto de mudanças climáticas globais que se desenha num futuro próximo. Enfim, no caso específico deste artigo, é evidente que a emigração Nordestina para outras regiões do país sempre teve estreita ligação com os fatores ambientais e é mencionada em grande parte da literatura ${ }^{13}$. O

MARTINE, George. Adaptação dos migrantes ou sobrevivência dos mais fortes?

8 BATES, Diane C. Environmental refugees? Classifying Human Migrations Caused by Environmental Change.

9 ADAMO, Susana B. Emigración y Ambiente: apuntes iniciales sobre un tema complejo.

${ }^{10}$ SALEHYAN, Idean. Refugees, Climate Change, and Instability.

11 MYERS, Norman. Environmental refugees; IDEM. Environmental refugees: A growing phenomenon of the 21 century.

12 OJIMA, Ricardo; NASCIMENTO, Thais. Meio Ambiente, Migração e Refugiados Ambientais: Novos Debates, Antigos Desafios.

${ }^{13}$ CAMARANO, Ana Amélia e ABRAMOVAY, Ricardo. Êxodo rural, Envelhecimento e Masculinização no Brasil: Panorama dos últimos 50 anos; CAMARANO, Ana Amélia. Movimentos migratórios recentes na região nordeste; DINIZ, Clélio C. O nordeste e o contexto nacional; OLIVEIRA, Kleber F. Demografia da pobreza em Sergipe: migração, renda e características municipais a partir dos anos 80; SANTOS, Tais F. e MOURA, Fernando A. Os determinantes da mortalidade infantil no nordeste: aplicação de modelos hierárquicos; TEIXEIRA, Pery. Mortalidade na infância, relações produtivas e pobreza no nordeste: um estudo estatístico e sócio-econômico; FUSCO, Wilson e DUARTE, Renato. Regiões metropolitanas no Nordeste: origens, destinos e retorno dos migrantes; FURTADO, Celso. A operação Nordeste. 
que não se observa, entretanto, é uma análise que coloque a questão ambiental no centro da discussão.

Assim, entender o emigrante nordestino enquanto "refugiado ambiental" é dar esse enfoque mais específico ao deslocamento condicionado por fatores ambientais. Este artigo, portanto, não visa dar o mesmo status político de refugiado aos movimentos motivados por questões ambientais ou climáticas, mas analisar o perfil do emigrante do semiárido setentrional e sua relação com fatores ambientais comparados a outros aspectos socioeconômicos, como por exemplo, os programas de transferência de renda enquanto mecanismos de proteção social e fixação dessa população na região.

Para tanto, o artigo inicialmente busca caracterizar o contexto socioambiental do semiárido setentrional e suas características demográficas para evidenciar o que a literatura já destaca como elementos importantes para a análise das migrações na região. Posteriormente, baseado nas informações da Secretaria Nacional de Proteção e Defesa Civil, do Ministério da Integração Nacional, sobre o reconhecimento de Situação de Emergência (SE) e Estado de Calamidade Pública (ECP) decorrente de secas nos municípios do semiárido setentrional entre os anos de 2007 e 2010, analisar o perfil dos emigrantes registrados pelo Censo Demográfico 2010 neste mesmo período.

Finalmente, em um esforço para entender o papel de algumas variáveis contextuais, domiciliares e individuais dos emigrantes, analisar as razões de chance de emigração do semiárido setentrional a partir da análise de um modelo logístico. Assim, poderíamos estimar a importância dos aspectos ambientais no contexto social dos emigrantes do semiárido setentrional. Longe, portanto, de confirmar ou refutar hipóteses sobre as motivações dos emigrantes, o trabalho busca colocar a dimensão ambiental no modelo explicativo das emigrações do semiárido para abrir o debate para uma agenda de pesquisa nesta região marcada por desigualdades sociais e carências socioeconômicas.

\section{O semiárido setentrional, população e a seca}

Segundo parte importante da literatura, a relação dos fluxos migratórios com mudanças ambientais deveria ser entendida como uma questão central no desenvolvimento regional, sobretudo pela recente preocupação sobre as políticas públicas, necessidades de redução das vulnerabilidades sociais e adaptação em um futuro de mudanças climáticas globais ${ }^{14}$. Assim, não deveria se

\footnotetext{
${ }^{14}$ BARBIERI, Alisson Flávio et alii. Climate change and population migration in Brazil's Northeast: scenarios for 2025-2050. BARBIERI, Alisson Flávio. Mudanças climáticas, mobilidade populacional e cenários de vulnerabilidade para o Brasil; HOGAN, Daniel J., MARANDOLA JUNIOR, Eduardo J. e OJIMA, Ricardo. População e Ambiente: Desafios à Sustentabilidade.
} 
restringir apenas aos "ambientalistas" a preocupação com medidas de adaptação aos dilemas ambientais ${ }^{15}$. Mas para tanto, o recorte de análise para captar essa relação dinâmica entre ambiente e população não pode se limitar ao políticoadministrativo, pois deveria incorporar os elementos naturais/ambientais que fazem sentido ao aspecto que se pretende estudar ${ }^{16}$.

A região Nordeste do Brasil concentra a segunda maior população do Brasil como indica o último Censo Demográfico, em 2010, com uma população de aproximadamente 53 milhões de habitantes. O que corresponde a 27,8\% da população brasileira. Proporção esta que pouco se alterou desde os anos 1980, quando os 34,8 milhões de habitantes da região, representavam $29,3 \%$ do total do país. Entretanto, quando analisamos o recorte do semiárido, notamos uma mudança mais significativa, pois em 1980, a população residente na região do semiárido correspondia a 45\% do total da região, enquanto que no ano de 2010, essa proporção passou para $40 \%$.

O "sertão norte", como também é conhecido o semiárido setentrional, considera os municípios do semiárido compreendidos nos estados do Piauí, Ceará, Rio Grande do Norte, Paraíba, Pernambuco e Alagoas. Esse recorte inclui um total de 754 municípios localizados na porção ao norte do Rio São Francisco, correspondente a $66,5 \%$ dos municípios do semiárido todo (que compreende também parte dos municípios da Bahia, Sergipe e Minas Gerais). Em 2010, viviam nessa região cerca de 14,1 milhões de habitantes e é a região do semiárido que contém o maior número de divisões político-administrativas, ou seja, com maior número de municípios e Unidades da Federação. E o foco específico de análise das migrações neste artigo será conduzido nessa região (ver FIG. 1) por ser a principal área de incidência de secas no Brasil.

Cabe destacar que, embora seja um recorte baseado em características ambientais, o semiárido brasileiro se constitui enquanto unidade de planejamento e ação governamental. A Portaria nº 89 do Ministério da Integração Nacional, de 2005, estabelece oficialmente os municípios que fazem parte do semiárido e, de acordo com o Plano de Desenvolvimento Estratégico do Semiárido (PDSA), desenvolve propostas de ação diferenciadas entre as sub-regiões do semiárido, incluindo o sertão norte. Sendo assim, apesar das características comuns, a região é heterogênea e o entendimento das dinâmicas migratórias nessa região deveria incorporar essa heterogeneidade.

\footnotetext{
${ }_{15}$ MARTINE, George et alii. População e sustentabilidade na era das mudanças ambientais globais: contribuições para uma agenda brasileira.

${ }^{16}$ HOGAN, MARANDOLA, OJIMA, op. cit.
} 


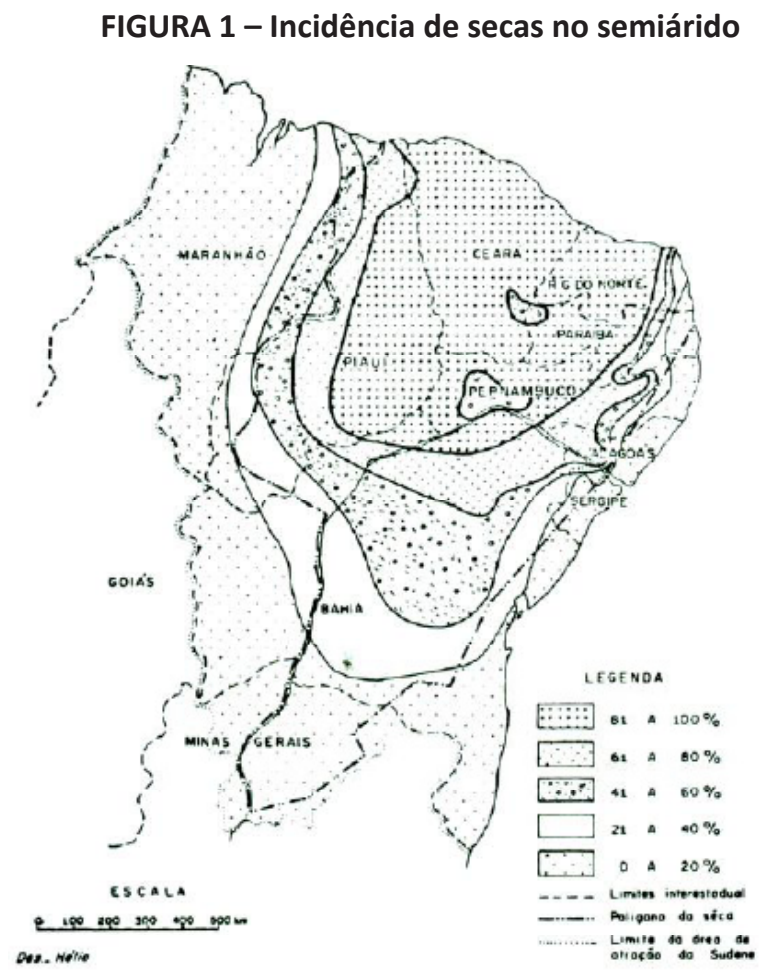

Fonte: Ab'Saber, 1999.

Os fatores climáticos se destacam na literatura como a causa básica da emigração dessa região e marcam a trajetória dos fluxos migratórios brasileiros enquanto um deslocamento forçado e uma das poucas estratégias de sobrevivência da população mais pobre frente aos desafios impostos por essa redução da capacidade de suporte. Sendo assim, inserir o emigrante nordestino nesta pauta de discussão requer uma analise gradual das condições climáticas do Nordeste brasileiro e dos períodos de intensa emigração em função dos períodos mais prolongados e severos da seca. Condição que pode ser mais crítica em pequenos e médios municípios que, em decorrência da sua menor capacidade de enfrentar os desafios ambientais devido à falta de recursos financeiros e humanos ${ }^{17}$, apresenta menores oportunidades para se adaptar aos efeitos do clima.

\footnotetext{
${ }^{17}$ OJIMA, Ricardo e MARANDOLA Jr., Eduardo. Indicadores e políticas públicas de adaptação às mudanças climáticas: vulnerabilidade, população e urbanização; OJIMA, Ricardo. Urbanização, Dinâmica Migratória e Sustentabilidade no Semiárido Nordestino: o papel das cidades no processo de adaptação ambiental.
} 
Em 2010, 75\% dos municípios do semiárido setentrional eram de pequeno porte populacional, ou seja, tinham até 20 mil habitantes. Estes mesmos municípios somados eram residência de 35\% do total de habitantes dessa região. Assim, mesmo que a região tenha reproduzido o processo de concentração demográfica em torno de cidades maiores, houve uma intensidade menos acentuada do que em outras regiões do país ${ }^{18}$. Há 50 anos a região Nordeste abrigava a maior parte da sua população em pequenos municípios rurais e hoje a situação permanece praticamente inalterada, a não ser pelo grau de urbanização que se acelerou nas últimas décadas. Portanto, embora as taxas de crescimento populacional da região sejam relativamente baixas (cerca de 1\% ao ano), as taxas de crescimento da população urbana se apresentam elevadas, mesmo se comparadas a outras regiões do país ${ }^{19}$.

Muito se tem discutido a respeito das causas que propiciaram o deslocamento em massa dos nordestinos paras outras regiões brasileiras, principalmente em períodos de forte desenvolvimento econômico nas áreas de destino, como a construção de Brasília, na década de 1950, o ciclo da borracha na região Norte do país, no início do século XX, e o processo de industrialização do Estado de São Paulo, na década de 1960. São fatos historicamente datados e que coincidem com as secas de 1951, 1958, 1970 e 1979-83. Ou seja, uma crescente demanda de mão de obra em regiões polarizadoras que atraíram migrantes nordestinos ao longo da história.

Desta forma, deve-se relativizar o contexto no qual essas ondas emigratórias ocorreram para entender melhor as relações entre migração e condicionantes ambientais no semiárido setentrional, pois em grande parte, essa diáspora sertaneja está relacionada ao contexto econômico e produtivo do período, no qual encontramos a decadência da economia baseada no complexo pecuária-algodão-subsistência versus o desenvolvimento industrial concentrado e da mão de obra em regiões do Sudeste brasileiro. É com o objetivo de analisar aspectos mais específicos desta relação população-ambiente-desenvolvimento que passaremos a discutir algumas características da emigração recente do semiárido setentrional com foco nos fatores de repulsão e das características seletivas destes emigrantes.

A partir dos dados disponibilizados pela Secretaria Nacional de Proteção e Defesa Civil20, entre os anos de 2007 e 2010, foram oficialmente reconhecidas

${ }^{18}$ CARVALHO, Otamar de; EGLER, Cláudio Antônio G. Alternativas de desenvolvimento para o Nordeste semi-árido: relatório final; OJIMA, op. cit.

${ }^{19}$ OJIMA, op. cit., p. 43.

${ }^{20}$ Dados disponíveis em setembro de 2014, através da página eletrônica do Ministério da Integração Nacional. As informações disponibilizadas no momento da consulta eram apenas para o período de 2097 a 2011. 
1.813 ocorrências de Situação de Emergência (SE) e Estado de Calamidade Pública (ECP) decorrente de secas nos 754 municípios do semiárido setentrional. Isso significa dizer que ao longo deste período um mesmo município declarou e teve reconhecida mais de uma vez uma SE ou ECP derivado de condições motivadas pela seca. Dos 754 municípios, apenas 17\% deles não tiveram reconhecimento oficial de SE ou ECP decorrente de secas, e $43 \%$ deles o tiveram mais de 3 vezes neste breve período.

\section{O perfil do "refugiado" nordestino}

Tomando como referência os dados de registros oficiais de SE e ECP motivados por secas nos municípios do semiárido setentrional entre os anos de 2007 e 2010 podemos dizer que a região confirmou a tendência tradicional de dificuldades enfrentadas pelas condições climáticas. Neste sentido, buscaremos aqui explicitar algumas características da população que emigrou desta região no mesmo período utilizando os dados provenientes do Censo Demográfico 2010, considerando os indivíduos que deixaram de residir no semiárido setentrional e, para fins de comparação, também a população que permaneceu nesta região ${ }^{21}$.

Nestes três anos finais da década, o semiárido apresentou um saldo migratório negativo da ordem de 206 mil pessoas que representavam 1,45\% da população residente em 2010. Esta emigração do semiárido setentrional possui uma clara seletividade por idade, concentrando quase metade das pessoas entre as idades de 20 a 34 anos. Portanto, uma população jovem e em idade ativa significativa sai da região do semiárido setentrional. Este fato deita suas raízes em uma proporção expressiva de pessoas que trabalham sem carteira assinada na região (36\%), o que se relaciona a uma região onde historicamente sempre existiram programas políticos incompletos e desintegrados de desenvolvimento regional ${ }^{22}$. Onde a participação relativa do valor adicionado bruto das atividades de "Administração, saúde e educação públicas e seguridade social" na economia da maioria absoluta dos municípios representa mais de $1 / 3$ do PIB municipal ${ }^{23}$.

O grau de urbanização no semiárido setentrional está abaixo da média do Nordeste, com $63,8 \%$ e $73,1 \%$, respectivamente. Mas mesmo sendo a grande região brasileira menos urbanizada, merece destacar que três em cada dez imigrantes que chegam ao semiárido setentrional o fazem para uma área rural. Situação inversa daqueles que emigram, pois estes vão majoritariamente viver em áreas urbanas em seus locais de destino. Entre os destinos dos emigrantes do semiárido setentrional, as cinco principais Unidades da Federação são, pela

\footnotetext{
${ }^{21}$ Excluiu-se da comparação os imigrantes para o semiárido no mesmo período.

22 AB'SABER, Aziz N. Sertões e sertanejos: uma geografia humana sofrida.

${ }^{23}$ IBGE - Instituto Brasileiro de Geografia e Estatística. Produto Interno Bruto dos Municípios 2011.
} 
ordem, São Paulo, Ceará, Rio Grande do Norte, Rio de Janeiro e Pernambuco. Sendo que São Paulo sozinho representa $31 \%$ dos destinos de todos os emigrantes dessa região. O Rio de Janeiro junto com São Paulo participam com $38 \%$ dos destinos migratórios dessa região. Fato que é expressivo e confirma a manutenção dos principais fluxos migratórios tradicionais brasileiros, embora a participação de migrações para a própria região Nordeste seja cada vez mais importante.

\section{Figura 2 - Estrutura etária por sexo dos emigrantes recentes com origem nos municípios do semiárido setentrional, 2007-2010}

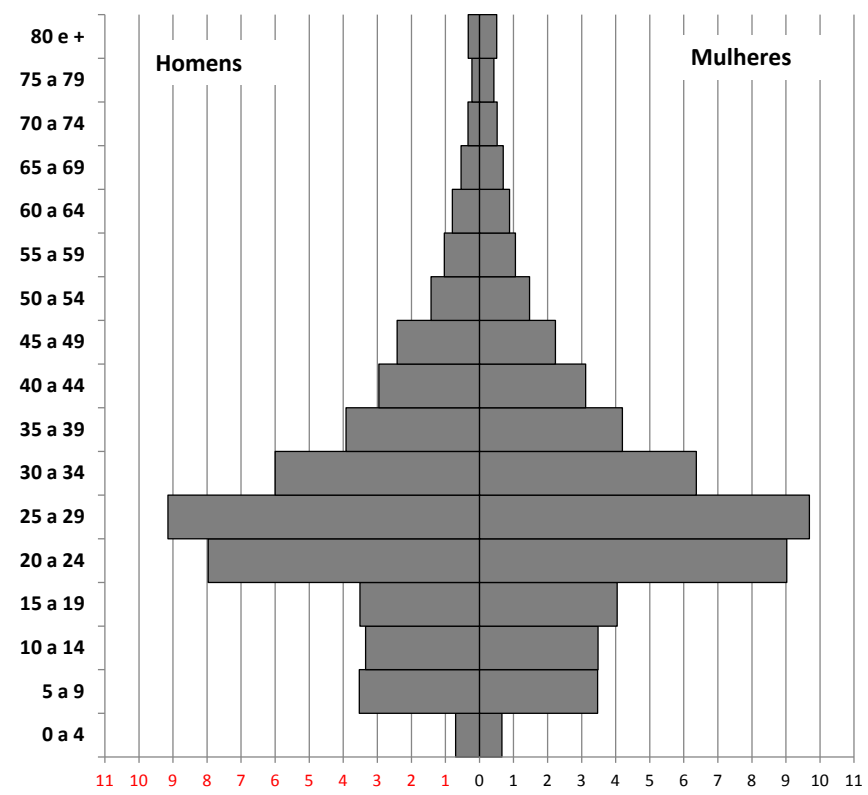

Fonte: IBGE, Censo Demográfico 2010.

Quando se analisam os principais municípios de destino, percebe-se que são as capitais os locais privilegiados para o fluxo. Sendo São Paulo, Fortaleza e Rio de Janeiro os principais municípios de destino. Merece destacar que o Rio Grande do Norte como terceira principal Unidade da Federação de destino dos emigrantes do semiárido setentrional divide quase todo o fluxo migratório para uma polarização entre três municípios da Região Metropolitana de Natal, incluindo sua sede Natal e somando-se a Parnamirim e São Gonçalo do Amarante.

Segundo Campos, Barbieri e Carvalho ${ }^{24}$, a migração possui um efeito importante do recebimento de benefícios de aposentadoria e pensão, pois

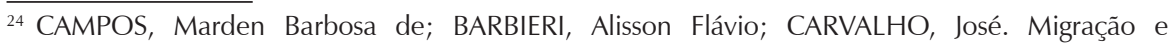
Previdência Social no Brasil entre 1980 e 2000. 
migração após a garantia da aposentadoria permitiria ao individuo obter maior autonomia na escolha do local de residência uma vez que deixa de ter constrangimento da necessidade do mercado de trabalho. Sendo assim, sobretudo numa região na qual o mercado de trabalho apresenta maior fragilidade (haja vista os já mencionados $36 \%$ de trabalhadores sem carteira assinada), não apenas a aposentadoria deveria apresentar um papel importante na decisão migratória.

Sendo assim, entre os emigrantes do semiárido setentrional, 83,8\% não recebem nenhum tipo de benefício social (aposentadoria, pensão, bolsa família, PETI ou outros). Proporção significativamente superior ao encontrado entre os residentes na região $(68,8 \%)$ e os que recém chegaram ao semiárido setentrional (77,5\%). Como apontado pela literatura, essa distribuição sugere que os benefícios sociais podem ter efeito tanto de atrair imigrantes (sobretudo os migrantes de retorno no caso do semiárido) como também de reduzir o ímpeto emigratório uma vez que é reduzida a proporção de emigrantes que recebem benefícios sociais.

Enfim, considerando a declaração de SE e ECP decorrente de secas, percebe-se que 13,6\% dos emigrantes são oriundos de municípios em que não houve registro oficial de seca. Entretanto, essa proporção é equivalente à população residente em municípios que não declararam secas. Essa análise nos leva a crer que o registro oficial de SE e ECP aparentemente não é um fator que distingue positivamente os emigrantes do semiárido setentrional. De fato, o registro oficial de SE e ECP motivado pela seca indica que houve comprometimento da capacidade de suporte de serviços nos municípios que o acionaram e, mesmo que a seca não tenha sido tão severa, o que este indicador permite avaliar é a capacidade de adaptação que os municípios possuem no combate às secas.

O fato de não haver uma proporção mais expressiva de emigrantes oriundos de municípios que declaram SE e ECP pode refletir formas de convivência com a seca por parte da população. De fato, essa ainda é uma região pouco urbanizada se comparada ao resto do país, entretanto nota-se que, apesar da proporção de pessoas com 10 anos e mais que declararam ter trabalhado na agropecuária de subsistência ter se mantido estável na faixa de $11 \%$ entre os Censos Demográficos de 2000 e 2010, a proporção de pessoas vivendo em áreas urbanas mudou de $58 \%$ para $63 \%$ neste mesmo intervalo de tempo.

Estratégias complementares com uma lógica urbana e agrícola, identificadas em contextos amazônicos ${ }^{25}$ parecem ter lugar também na região do

${ }^{25}$ VANWEY, Leah K.; GUEDES, Gilvan R; D'ANTONA, Álvaro O. Land use change in Altamira settlement area, Pará, Brazil: patterns associated with property owner migration or ownership change; D'ANTONA, Álvaro de Oliveira e VANWEY, Leah K. Rural urbanization in the Brazilian Amazon: factors endogenous to the region and rural households in Santarém, Pará. 
semiárido setentrional ${ }^{26}$ apontando para uma urbanização extensiva na região ${ }^{27}$. Uma lógica complementar que teria especificidades em relação ao contexto amazônico, pois em se tratando de uma região semiárida, as condições materiais para atividades agrícolas assumem um papel muito mais complexo e dependente do clima. Assim, seria necessário conduzir pesquisas qualitativas mais específicas para testar esta hipótese que os grandes números sugerem.

Outro elemento de transformação no semiárido setentrional nesta última década foi o aumento da importância dos deslocamentos entre municípios de residência e trabalho diferentes (pendularidade). Considerando a população residente nos municípios do semiárido setentrional, a proporção de pessoas que faziam deslocamentos para outros municípios para trabalho em 2000 era de 2,3\%, enquanto que em 2010 essa proporção sobe para 3,6\%. Como destacado por Ojima e Marandola J $\mathrm{r}^{28}$, esse fenômeno se dissemina e deixa de ser fenômeno exclusivamente metropolitano e passa a se articular como estratégias para evitar a mudança de residência (migração) associada ao desenvolvimento local de alguns polos regionais.

Assim, municípios de pequeno porte, mas que se consolidam enquanto pólos de geração de empregos acomodam a população regional em torno de sua atratividade evitando também que emigrações para regiões mais distantes e até mesmo para o próprio município de destino da pendularidade ocorram. São os casos de municípios como Guamaré (RN), Toritama (PE) e Horizonte (CE) em que os deslocamentos pendulares correspondem a uma proporção expressiva da sua população residente. Este tipo de mobilidade torna-se mais um mecanismo de adaptação que reduz o ímpeto das emigrações de média e longa distância e constitui-se em elemento importante para se entender a dinâmica das migrações contemporâneas.

\section{Secas, políticas sociais e migrações}

Dando continuidade à análise do perfil dos emigrantes do semiárido setentrional, compararam-se as chances do indivíduo ser emigrante do semiárido setentrional utilizando-se a análise de regressão logística. Para isso foram excluídos do estudo os indivíduos residentes no semiárido setentrional com tempo de residência no município inferior a três anos. Ou seja, para a análise foram comparados os indivíduos que em 2010 residiam fora do semiárido setentrional, mas indicaram ter residido anteriormente em algum município dessa região e os indivíduos que residiam no semiárido setentrional, mas que não haviam chegado de fora do semiárido recentemente.

\footnotetext{
${ }^{26}$ OJIMA, op. cit.

${ }^{27}$ MONTE-MÓR, Roberto L. O que é o urbano no mundo contemporâneo.

${ }^{28}$ OJIMA, MARANDOLA, op. cit.
} 
A variável dependente (MIGRA) refere-se à condição de migração dos indivíduos (emigrante ou residente), nos últimos três anos (última etapa), em relação ao semiárido setentrional. Essa variável foi derivada dos quesitos do Censo sobre o tempo de moradia no município (V0624) e município de residência anterior (V6254). As variáveis independentes (ou covariáveis) do estudo foram: (1) sociodemográficas (idade, sexo nível de instrução, presença de cônjuge ou companheiro, preceptor de algum benefício social, beneficiário do programa Bolsa Família, beneficiário do INSS) e (2) indicador se o município decretou SE ou ECP em decorrência de seca ou estiagem.

\section{Quadro 1 - Variáveis independentes incluídas na análise}

\begin{tabular}{|c|c|c|}
\hline Variável & Descrição & Categorias \\
\hline IDADE & Idade em anos, agrupada em faixas de idade & 20 a 39 \\
\hline & & 40 a 59 \\
\hline & Informação sobre o Nível de instrução & Sem instrução ou fundamental incomp. \\
\hline INSTRUCAO & Sexo do indivíduo & Fundamental completo \\
\hline & & Médio completo ou mais \\
\hline SEXO & & Feminino \\
\hline & Informação se vive com cônjuge ou companheiro & Masculino \\
\hline CONJUGE & & Sim \\
\hline & & Não \\
\hline BENEFSOCIAL & Informação se é preceptor de algum benefício social & Sim \\
\hline & & Não \\
\hline INSS & Informação se é beneficiário do INSS & Sim \\
\hline & & Não \\
\hline PBF & Informação se é beneficiário do programa Bolsa Família & Sim \\
\hline & & Não \\
\hline SECA & Informação se o município decretou estado de calamidade & São \\
\hline & &
\end{tabular}

Modelos de regressão logística simples e múltipla foram ajustados para avaliar a associação entre condição de migração e fatores associados. Para a variável dependente, a categoria de referência é ser residente. Assim, a chance de ser emigrante é expressa por $\mathrm{p} /(1-\mathrm{p})$ que denota a probabilidade de ser emigrante sobre a probabilidade de não ser emigrante (ou seja, ser residente). A razão de chances para uma dada covariável é estimada como sendo a chance dos indivíduos que estão na categoria correspondente de serem emigrantes sobre a chance da categoria de referência de serem emigrantes. A equação do modelo logístico é expressa por: 


$$
\log \left(\frac{p}{1-p}\right)=\alpha+\beta_{1} X_{1}+\beta_{2} X_{2}+\beta_{3} X_{3}+\ldots+\beta_{p} X_{p}
$$

Na equação (1) os valores dos parâmetros estimados $\beta$ i (coeficientes das covariáveis) mostram a mudança no logito (p), associado a uma mudança unitária na covariável, quando todas as outras variáveis são mantidas constantes. O coeficiente do termo constante $(\alpha)$ mostra o valor do logito (p) quando todas as covariáveis têm valor igual a zero (categorias de referência) e X1, X2 a Xp representam o vetor das variáveis independentes ${ }^{29}$.

Procederam-se análises ${ }^{30}$ univariadas e múltiplas, com o cálculo de razão de chances (OR) bruta e ajustada, respectivamente. Intervalos de 95\% de confiança (IC95\%) foram estimados para as OR; não se considerou estatisticamente significante as estimativas de OR que incluíam o valor "um" nos respectivos IC95\%. Considerando-se a importância do recebimento de benefícios sociais na composição da renda e possível impacto sobre a decisão de emigrar, foram ajustados três modelos logísticos para melhor avaliar o efeito dessa variável: modelo 1 - considerou o recebimento de qualquer benefício social; modelo 2 - o recebimento de bolsa família e modelo 3 - o recebimento de benefício do INSS.

Na análise dos fatores associados à emigração, os resultados obtidos com os modelos logísticos múltiplos (Tabela 1) demonstraram que o fato do município ter decretado estado de calamidade não se constitui como principal fator na decisão de migrar. Com 95\% de confiança, as chances de ser emigrante são as mesmas entre os indivíduos residentes em municípios que decretaram estado de seca e os seus congêneres de municípios que não decretaram calamidade. Descrevemos a seguir uma análise mais detalhada dos resultados obtidos com o modelo logístico.

No modelo 1, em que se avalia o efeito do recebimento de algum tipo de benefício social na composição dos rendimentos mensais, o mesmo foi o principal fator associado à emigração. Observa-se que, mantendo-se os demais fatores constantes, indivíduos que não recebiam nenhum benefício social apresentaram maior chance de ser emigrante (OR: 2,56; IC95\%: 2,47 - 2,65). Ou seja, de alguma forma, o recebimento de benefícios sociais no incremento da renda auferida funcionaria como um fator de retenção no processo de migrar. Sendo assim, uma vez que o processo de emigração pressupõe um custo no seu deslocamento, pode-se considerar que aqueles indivíduos que emigram têm uma condição financeira prévia ou economia que permite assumir este custo.

\footnotetext{
${ }^{29}$ HOSMER, David W.; LEMESHOW, Stanley. Applied logistic regression.

${ }^{30}$ As analises estatísticas foram realizadas com o Software SPSS versão 17 (SPSS Inc., Chicago, Illinois, U.S.A), com o auxilio do módulo csplan que permite incorporar o delineamento da amostra complexa e pesos amostrais do Censo 2010.
} 
Diferentemente dos indivíduos que são preceptores de benefícios sociais que já denotam uma situação financeira mais precária e teriam maiores dificuldades para custear um deslocamento para um município fora do semiárido setentrional.

Tabela 1 - Estimativas de razões de chance (OR) para condição de migração (emigrante/residente) no semiárido setentrional, segundo características selecionadas. Semiárido setentrional - Brasil, 2010

\begin{tabular}{|c|c|c|c|c|}
\hline \multirow[t]{2}{*}{ Variáveis } & \multirow{2}{*}{$\begin{array}{l}\text { OR bruta } \\
\text { (IC 95\%) }\end{array}$} & \multicolumn{3}{|c|}{ OR ajustada (IC 95\%) } \\
\hline & & Modelo 1 & Modelo 2 & Modelo 3 \\
\hline \multicolumn{5}{|l|}{ BENEFSOCIAL } \\
\hline Não & $3,03(2,95-3,12)$ & $2,56(2,47-2,65)$ & - & - \\
\hline Sim & Ref. & Ref. & & \\
\hline \multicolumn{5}{|l|}{ PBF } \\
\hline Não & $2,56(2,46-2,66)$ & - & $3,50(3,35-3,65)$ & - \\
\hline Sim & Ref. & & Ref. & \\
\hline \multicolumn{5}{|l|}{ INSS } \\
\hline Não & $3,05(2,92-3,18)$ & - & - & $1,55(1,46-1,65)$ \\
\hline Sim & Ref. & & & Ref. \\
\hline \multicolumn{5}{|l|}{ SECA } \\
\hline $\operatorname{Sim}$ & $1,01(0,97-1,05)$ & $1,00(0,96-1,04)$ & $1,00(0,96-1,05)$ & $0,99(0,95-1,04)$ \\
\hline Não & Ref. & Ref. & Ref. & Ref. \\
\hline \multicolumn{5}{|l|}{ IDADE } \\
\hline 20 a 39 & $3,99(3,81-4,18)$ & $2,01(1,91-2,12)$ & $4,26(4,06-4,47)$ & $2,39(2,23-2,56)$ \\
\hline 40 a 59 & $1,79(1,7-1,88)$ & $1,00(0,94-1,05)$ & $1,94(1,84-2,04)$ & $1,19(1,11-1,27)$ \\
\hline 60 ou mais & Ref. & Ref. & Ref. & Ref. \\
\hline \multicolumn{5}{|l|}{ INSTRUCAO } \\
\hline $\begin{array}{l}\text { Sem instrução ou } \\
\text { fundamental incompleto }\end{array}$ & & Ref. & Ref. & Ref. \\
\hline $\begin{array}{l}\text { Fundamental completo } \\
\text { e médio incompleto }\end{array}$ & $1,90(1,85-1,95)$ & $1,36(1,32-1,41)$ & $1,37(1,33-1,42)$ & $1,47(1,42-1,52)$ \\
\hline $\begin{array}{c}\text { Ensino médio } \\
\text { completo ou mais }\end{array}$ & $1,95(1,89-2,02)$ & $1,22(1,18-1,26)$ & $1,20(1,17-1,24)$ & $1,44(1,40-1,48)$ \\
\hline \multicolumn{5}{|l|}{ SEXO } \\
\hline Feminino & $1,01(0,99-1,02)$ & $1,30(1,27-1,33)$ & $1,33(1,31-1,36)$ & $1,00(0,98-1,02)$ \\
\hline Masculino & Ref. & Ref. & Ref. & Ref. \\
\hline \multicolumn{5}{|l|}{ CONJUGE } \\
\hline Sim & $1,09(1,06-1,12)$ & $1,27(1,23-1,30)$ & $1,34(1,3-1,38)$ & $1,18(1,15-1,22)$ \\
\hline Não & Ref. & Ref. & Ref. & Ref. \\
\hline
\end{tabular}

As chances de ser emigrante também foram maiores para os grupos etários de 20 a 29 anos comparativamente ao grupo etário com 60 ou mais anos 
de idade. Em relação ao efeito da escolaridade, observou-se que os indivíduos com maiores chances de emigração foram aqueles que no mínimo já tinham completado o ensino fundamental comparativamente aos indivíduos com nível inferior de instrução. Maiores chances de ser emigrante do semiárido setentrional também foram observadas para as mulheres (1,30; IC95\%: 1,27 - 1,33) e para indivíduos que moravam com cônjuge ou companheiro(a) (OR:1,27; IC95\%: $1,23-1,30)$.

No modelo 2, que captura o efeito do benefício do Programa Bolsa Família (PBF), as variáveis analisadas apresentaram associações semelhantes ao modelo 1. Destaca-se o aumento da intensidade e a relação linear das chances de ser emigrante para a variável idade. As chances de emigrar aumentam conforme se compara o grupo de maior faixa-etária em relação aos dois grupos de menor idade. Para aqueles que não são beneficiários do PBF, as chances de ser emigrante é 3,5 (IC95\%: 3,35 - 3,65) maior em relação aos seus congêneres preceptores do benefício.

No modelo 3, ao substituirmos a variável referente ao recebimento de Bolsa Família, presente no modelo 2, pelo recebimento de benefício do INSS (aposentadoria ou pensão), observou-se que, mantendo-se os demais fatores constantes, os indivíduos que não recebiam esse benefício apresentaram maiores chances de migrar em relação aos indivíduos preceptores desse benefício (OR:1,55; IC95\%: 1,46 - 1,65). O sexo não se mostrou um fator associada ao processo de migrar, diferentemente dos resultados verificados nos modelos 1 e 2. Ainda em relação aos modelos anteriores, observou-se um aumento no efeito da variável escolaridade, de forma que indivíduos com ensino fundamental completo apresentaram 1,47 (1,42-1,52) vezes mais chances de emigrar em relação aqueles com nível inferior de instrução.

\section{Considerações finais}

Como pudemos perceber na análise conduzida neste artigo, o fato do indivíduo residir ou não em município do semiárido setentrional que tenha decretado Situação de Emergência ou Estado de Calamidade Pública devido à seca não se constitui como um fator estatisticamente significante para explicar o motivo da emigração dessa região. Neste sentido, confirma-se o que a literatura discute sobre a dificuldade de se encontrar uma relação com fatores climáticos e ambientais. De fato, o que pudemos perceber é que fatores socioeconômicos associados ao recebimento de benefícios de programas sociais possuem muito mais peso na emigração dos indivíduos dessa região.

Como destacado pelo Modelo 2 desenvolvido na análise de regressão logística, o não recebimento de benefício do PBF aumenta em 3,5 vezes a 
chance do indivíduo ser emigrante. Essa razão de chance pode ser explicada por dois lados: o indivíduo emigrante é carente e busca na emigração novas formas de mobilidade social ou também o fato de que o emigrante típico não pode ser tão vulnerável socioeconomicamente e por isso ele não seria elegível ao recebimento de programas sociais como o PBF. Embora a segunda explicação seja muito plausível, observando a análise do Modelo 3 que inclui o recebimento de benefício do INSS, pode-se perceber que é maior a chance de emigrar não sendo beneficiário. Assim, seria correto afirmar que as políticas sociais, de alguma forma, se apresentam como fatores de retenção da população no semiárido setentrional.

Neste sentido, pelo menos no que se refere aos dados mais recentes, é muito pouco clara a relação do registro oficial de secas e os fluxos de emigração na região do semiárido setentrional. Segundo a literatura, os refugiados ambientais deveriam aumentar com o agravamento das condições extremas do clima, entretanto, pela análise conduzida aqui, haveria mais emigrantes conforme os programas sociais de transferência de renda se tornem menos importantes na região. Ou seja, a seca é muito menos importante do que a existência de mecanismos de proteção social para a ocorrência de emigração na região.

Portanto, investir em programas e mecanismos de proteção social e estratégias de convivência com a seca é mais impactante para a manutenção da população no semiárido setentrional. Enfim, as mudanças climáticas devem contribuir com o acirramento de problemas sociais existentes, mas considerando que não se criarão novos problemas ambientais e essas mudanças ocorrerão de modo lento e gradativo, há que se ter cautela com a categorização de novos fluxos migratórios enquanto "refugiados ambientais" nessa região. De toda forma ainda são poucos estudos que se debrucem com mais detalhamento sobre estas relações. Sendo assim, esta breve análise buscou lançar luz sobre um aspecto que ainda merece muita investigação, sobretudo, pela carência de estudos demográficos que utilizem este recorte territorial particular e único no mundo.

\section{Referências bibliográficas}

AB'SABER, Aziz N. Sertões e sertanejos: uma geografia humana sofrida. Estudos Avançados, IEA/USP, São Paulo, v. 13, n. 36, 1999, p. 7-59.

ADAMO, Susana B. Emigración y Ambiente: apuntes iniciales sobre un tema complejo. Papeles de la población. México, jul/set 29, 2001, p. 143-159.

BARBIERI, Alisson Flávio; DOMINGUES, Edson; QUEIROZ, Bernardo; RUIZ, Ricardo; RIGOTI José; CARVALHO, José; RESENDE, Marco. Climate change and population migration in Brazil's Northeast: scenarios for 2025-2050. Population and Environment, v. 31, 2010, p. 344-370.

BARBIERI, Alisson Flávio. Mudanças climáticas, mobilidade populacional e cenários 
de vulnerabilidade para o Brasil. REMHU - Rev. Interdiscip. Mobil. Hum, Brasília, v. 19, n. 36, 2011, p. 95-112.

BATES, Diane C. Environmental refugees? Classifying Human Migrations Caused by Environmental Change. Population and environment, Human Science Press, v. 23, n. 5, 2002, p. 465-477.

CAMARANO, Ana Amélia; ABRAMOVAY, Ricardo. Êxodo rural, Envelhecimento e Masculinização no Brasil: Panorama dos últimos 50 anos. Rio de Janeiro: IPEA, 1999.

CAMARANO, Ana Amélia. Movimentos migratórios recentes na região nordeste. Anais do I Encontro Nacional sobre Migrações. Curitiba: ABEP, 1997.

CAMPOS, Marden Barbosa de; BARBIERI, Alisson Flávio; CARVALHO, José. Migração e Previdência Social no Brasil entre 1980 e 2000. In Mudança populacional: aspectos relevantes para a Previdência. Brasília: MPS, SPPS, 2008.

CARVALHO, Otamar de; EGLER, Cláudio Antônio G. Alternativas de desenvolvimento para o Nordeste semi-árido: relatório final. Fortaleza: Banco do Nordeste do Brasil, 2003.

D'ANTONA, Álvaro de Oliveira; VANWEY, Leah K. Rural urbanization in the Brazilian Amazon: factors endogenous to the region and rural households in Santarém, Pará. In 7th International Science Conference on the Human Dimensions of Global Environmental Change. Bonn, 2009.

DINIZ, Clélio C. O nordeste e o contexto nacional. Anais do VI Encontro Nacional de Estudos Populacionais. ABEP: Olinda. 1988.

EL-HINNAWI, Essam. Environmental refugees. Nairobi: United Nations Environment Programme, 1985.

FURTADO, Celso. A operação Nordeste. Rio de Janeiro: Ministério da Educação e Cultura, Instituto Superior de Estudos Brasileiros, 1959.

FUSCO, Wilson; DUARTE, Renato. Regiões metropolitanas no Nordeste: origens, destinos e retorno dos migrantes. Anais do XVII Encontro Nacional de Estudos Populacionais. Caxambu: ABEP, 2010.

HOSMER, David W.; LEMESHOW, Stanley. Applied logistic regression. New York: J. Wiley, 1989.

HOGAN, Daniel J.; MARANDOLA Jr., Eduardo J.; OJIMA, Ricardo. População e Ambiente: Desafios à Sustentabilidade. São Paulo: Blucher, 2010.

HOGAN, Daniel J. Mobilidade populacional, sustentabilidade ambiental e vulnerabilidade social. Revista Brasileira de Estudos da População, São Paulo, v. 22, n. 2, 2005, p. 323-338.

IBGE - Instituto Brasileiro de Geografia e Estatística. Produto Interno Bruto dos Municípios 2011. Rio de Janeiro: IBGE, 2011.

LEE, Everett S. Uma teoria sobre a migração. In MOURA, Hélio (org.). Migração Interna - textos selecionados. Fortaleza: Banco do Nordeste do Brasil S.A., 1980.

MARTINE, George. Adaptação dos migrantes ou sobrevivência dos mais fortes? In MOURA, Hélio (org.). Migração interna: textos selecionados. Fortaleza: Banco do Nordeste do Brasil S.A., 1980. 
MARTINE, George; OJIMA, Ricardo; BARBIERI, Alisson Flávio; CARMO, Roberto L. População e sustentabilidade na era das mudanças ambientais globais: contribuições para uma agenda brasileira. Campinas: ABEP, 2012.

MONTE-MÓR, Roberto L. O que é o urbano no mundo contemporâneo. Texto para Discussão. Belo Horizonte: Cedeplar/UFMG, n. 281, 2006.

MORRISEY, James. Rethinking the 'debate on environmental refugees': from 'maximilists and minimalists' to 'proponents and critics'. Journal of Political Ecology, v. 19, 2012.

MYERS, Norman. Environmental refugees. Population and Environment, Human Science Press, v. 19, n. 2, 1997, p. 167-182.

. Environmental refugees: A growing phenomenon of the 21 century. The Royal Society, 2001.

OJIMA, Ricardo. Urbanização, Dinâmica Migratória e Sustentabilidade no Semiárido Nordestino: o papel das cidades no processo de adaptação ambiental. Cadernos Metrópole (PUCSP), v. 15, 2013, p. 35-54.

OJIMA, Ricardo; MARANDOLA Jr., Eduardo J. Indicadores e políticas públicas de adaptação às mudanças climáticas: vulnerabilidade, população e urbanização. Revista Brasileira de Ciências Ambientais, v. 18, 2011, p. 16-24.

OJIMA, Ricardo; MARANDOLA, Eduardo J. Mobilidade populacional e um novo significado para as cidades: dispersão urbana e reflexiva na dinâmica regional não metropolitana. Revista Brasileira de Estudos Urbanos e Regionais (ANPUR), v. 14, 2012, p. 103-116.

OJIMA, Ricardo; NASCIMENTO, Thais T. Meio Ambiente, Migração e Refugiados Ambientais: Novos Debates, Antigos Desafios. In IV Encontro Nacional da Associação Nacional de Pesquisa e Pós-graduação em Ambiente e Sociedade (ANPPAS). Anais... Brasília: ANPPAS, junho/2008.

OLIVEIRA, Kleber F. Demografia da pobreza em Sergipe: migração, renda e características municipais a partir dos anos 80. Tese de Doutorado. Universidade Estadual de Campinas. Instituto de Filosofia e Ciências Humanas. Campinas, SP : [s. n.], 2008.

OLIVEIRA, Kleber F.; JANNUZZI, Paulo M. Motivos para migração no Brasil e retorno ao Nordeste: padrões etários, por sexo e origem/destino. São Paulo em Perspectiva, v. 19, n. 4, out/dez, 2005, p. 134-143.

ONU - ORGANIZAÇÃO DAS NAÇÕES UNIDAS. Convenção de Genebra. Estatuto do Refugiado, 1951. Disponível em: <http://goo.gl/5f6mWa>. Acesso em: 09/2014.

SALEHYAN, Idean. Refugees, Climate Change, and Instability. In Human Security and Climate Change - International Workshop. Oslo (Norway), 21-23 June, 2005.

SANTOS, Tais F.; MOURA, Fernando A. Os determinantes da mortalidade infantil no nordeste: aplicação de modelos hierárquicos. Anais do VII Encontro Nacional de Estudos Populacionais. Caxambu: ABEP, 1990.

SUHRKE, Astri. Environmental degradation and population flows. Journal of International Affairs, v. 47, n. 2, 1994, p. 473-496. 
TEIXEIRA, Pery. Mortalidade na infância, relações produtivas e pobreza no nordeste: um estudo estatístico e sócio-economico. Anais do XI Encontro Nacional de Estudos Populacionais. Caxambu: ABEP, 1998.

VANWEY, Leah K.; GUEDES, Gilvan R.; D'ANTONA, Álvaro O. Land use change in Altamira settlement area, Pará, Brazil: patterns associated with property owner migration or ownership change. In The Annual Meeting of the Population Association of America [Proceedings...]. Nova Orleans, Silver Spring: MD, PAA, 2008.

\section{Abstract}

\section{"My life is walk through the country...": recent out-migration in the northern semiarid, social policies and environment}

The environmental refugee category has been used to describe the displacement caused by extreme weather conditions. Estimates are that there will be a significant increase in this type of movement in the coming years, mainly by worsening environmental conditions resulting from climate change. However, there is considerable controversy regarding the importance of environmental factors on migratory decision. In this sense, the article seeks to bring a reflection on the relevance of environmental refugee category in the context of out-migration from northern semiarid region, the more burdened by drought. For this we use the official data of decree Emergency Situation (SE) and the State of Public Calamity (ECP) and 2010 Census data to analyze the profile and the role that environmental and social factors can have on migrants. The results indicate that the absence of income transfer programs have a more important role than the official droughts among out-migration from this region. Although the results need further investigation, the evidence points to strategies that contribute to greater resilience of the people are effective for coping with drought.

Keywords: out-migration, Northern Semiarid, environmental displacements, social policies.

Recebido para publicação em 21/09/2014.

Aceito para publicação em 06/11/2014. Received for publication in September, $21^{\text {th }}, 2014$. Accepted for publication in November, 06 ${ }^{h}, 2014$.

ISSN impresso: 1980-8585

ISSN eletrônico: 2237-9843

http://dx.doi.org/10.1590/1980-85852503880004310 